\title{
Monitoring Cr toxicity and remediation processes - combining a whole-cell bioreporter and Cr isotope techniques
}

\author{
Qiong Zhang ${ }^{\mathrm{a}}$, Yizhi Song ${ }^{\mathrm{b}}$, Ken Amor ${ }^{\mathrm{a}}$, Wei E. Huang ${ }^{\mathrm{b}}$, Don Porcelli ${ }^{\mathrm{a}}$, Ian Thompson ${ }^{\mathrm{b}}$ \\ ${ }^{a}$ Department of Earth Sciences, University of Oxford, South Parks Road, Oxford, OX1 3AN United Kingdom. \\ ${ }^{b}$ Department of Engineering Science, University of Oxford, Parks Road, Oxford, OX1 3PJ, United Kingdom.
}

\section{Abstract}

Bioremediation is a sustainable and cost-effective means of contaminant detoxification. Although $\mathrm{Cr}(\mathrm{VI})$ is toxic at high concentrations, various microbes can utilise it as an electron accepter in the bioremediation process, and reduce it to the less toxic form $\mathrm{Cr}(\mathrm{III})$. During remediation, it is important to monitor the level of toxicity and effectiveness of $\mathrm{Cr}(\mathrm{VI})$ reduction in order to optimize the conditions. This study employed a whole-cell bioreporter Acinetobacter baylyi ADPWH-recA to access the degree of toxicity of different species of $\mathrm{Cr}$ over a range of initial concentrations. It also investigated whether $\mathrm{Cr}$ isotope fractionation factors were impacted by different levels of $\mathrm{Cr}$ toxicity (related to its concentration) and $\mathrm{Cr}(\mathrm{VI})$ reduction rates by $\mathrm{Cr}$ resistant bacteria Pseudomonas fluorescens LB 300. The results show that, of both $\mathrm{Cr}_{2} \mathrm{O}_{7}^{2-}$ and $\mathrm{CrO}_{4}^{2-}$, the whole-cell bioreporter was efficient in indicating the level of genotoxicity of $\mathrm{Cr}(\mathrm{VI})$ at low concentrations and cytotoxicity at high concentrations via variations of bioluminescence. High concentrations $(>100$ $\mathrm{mg} / \mathrm{L}$ ) of $\mathrm{Cr}(\mathrm{III})$ could also strongly induce the luminescence in the bioreporter, indicating DNA damage at such abundance. Pseudomonas fluorescens LB 300 was found to be effective in reducing $\mathrm{Cr}(\mathrm{VI})$ even when the concentration was high $(40 \mathrm{mg} / \mathrm{L})$; however, complete $\mathrm{Cr}(\mathrm{VI})$ reduction was only observed at low concentrations $(<5 \mathrm{mg} / \mathrm{L})$, since the toxicity of high concentrations of $\mathrm{Cr}(\mathrm{VI})$ impacted the effectiveness of reduction by the bacteria. During reduction, the ${ }^{53} \mathrm{Cr} /{ }^{52} \mathrm{Cr}$ ratio of remaining $\mathrm{Cr}(\mathrm{VI})$ increased from its initial value, and the calculated fractionation factor by bacterial $\mathrm{Cr}(\mathrm{VI})$ reduction $(\varepsilon)$ was $-3.1 \pm 0.3 \%$. The fractionation factor was independent of the initial $\mathrm{Cr}(\mathrm{VI})$ concentration. Therefore, a single $\mathrm{Cr}$ isotope fractionation factor can be effectively applied in indicating the extent of bioremediation processing of $\mathrm{Cr}(\mathrm{VI})$ over a wide range of concentrations. This significantly simplified monitoring of $\mathrm{Cr}(\mathrm{VI})$ depletion in bioremediation, 
since variations of $\varepsilon$ normally indicate a change in the reduction mechanism and therefore would complicate the elucidation of processes driving the remediation.

\section{Keywords:}

chromium, isotopes, bacterial reduction, whole-cell bioreporters

\section{Introduction}

Hexavalent chromium is widely used in industries for corrosion inhibition, electroplating, paints, pigment manufacturing and leather tanning, and therefore is a common contaminant in the natural environment (Desai et al., 2008). Various studies show that $\mathrm{Cr}(\mathrm{VI})$ has very high solubility and bioavailability (Antonini and Roberts, 2007, Dayan and Paine, 2001). Moreover, toxicity studies demonstrate that $\mathrm{Cr}(\mathrm{VI})$ can induce oxidative stress in cells, causing DNA damage, gene mutation, sister chromatid exchange, chromosomal aberrations, cell transformation, and dominant lethal mutations in a number of targets in both animal and human cells. In humans, the lethal oral dose of soluble chromates is considered to be 50 - $70 \mathrm{mg} / \mathrm{kg}$ body weight. The acute poisoning of $\mathrm{Cr}(\mathrm{VI})$ can induce vomiting, diarrhoea, haemorrhage, and blood loss into the gastrointestinal tract that can cause cardiovascular shock. Chronic toxic effects in humans include liver and kidney necrosis (Dayan and Paine, 2001).

In the environment, $\mathrm{Cr}(\mathrm{VI})$ pollution can alter the structure of soil microbial communities, reducing microbial growth and enzymatic activities. Laboratory based studies indicate that it can also induce cellular oxidative stress in microorganisms, and that the cellular defence against the toxicity involves activation of antioxidant mechanisms (Ackerley et al., 2006). The toxicity of $\mathrm{Cr}(\mathrm{VI})$ towards microorganisms can also inhibit the biodegradation of other organic pollutants (Kourtev et al., 2006). As with mammalian cells, in bacteria, $\mathrm{Cr}(\mathrm{VI})$ is highly toxic at the extracelluar level because it can rapidly enter the cytoplasm. Its toxicity in the cytoplasm is mainly related to the reduction process that generate free radicals (Ramirez-diaz et al., 2008).

$\mathrm{Cr}(\mathrm{VI})$ can be reduced to $\mathrm{Cr}(\mathrm{III})$, which is generally found to have much lower bioavailability and toxicity than Cr(VI) (Dayan and Paine, 2001, Zhang et al., 2011). However, other studies suggest that $\mathrm{Cr}(\mathrm{III})$ could also be toxic to microbes by causing DNA damage (Plaper et al., 2002) 
or by altering the $\mathrm{pH}$ (Garcia et al., 1994) in the surrounding environs. Nevertheless, in the natural environment, $\mathrm{Cr}(\mathrm{III})$ is more insoluble and surface-reactive than $\mathrm{Cr}(\mathrm{VI})$, and is consequently less mobile and bioavailable.

Due to the seriousness of $\mathrm{Cr}(\mathrm{VI})$ pollution and its significant effects on human health, $\mathrm{Cr}(\mathrm{VI})$ is classified as a class A human carcinogen by the US Environmental Protection Agency (USEPA) (Desai et al., 2008) and recommends safe levels of not more than $0.05 \mathrm{ppm}$ in unpolluted areas. Therefore, monitoring and controlling of pollutant $\mathrm{Cr}(\mathrm{VI})$ are clearly very important.

Remediation of $\mathrm{Cr}(\mathrm{VI})$ pollution commonly centres on its transformation to less toxic oxidation states. Compared with most conventional physicochemical methods, biological $\mathrm{Cr}(\mathrm{VI})$ detoxification is an eco-friendly and cost-effective alternative in various environments and in industry. Many microorganisms, such as Bacillus. sp (Pan et al., 2014), Pseudomonas.sp (Park et al., 2000), Escherichia coli (Ackerley et al., 2004) and Shewanella. sp (Hossain et al., 2005), have proven to have great ability to adapt and colonise noxious metal-polluted environments, and to transform the oxidation state of $\mathrm{Cr}$. However, microbes have their own limitations towards highly toxic contaminants, which can cause severe damage to their function or even viability. Therefore, the assessment of environmental risks to microbial communities associated with aqueous and soil contamination is very important before instigating any bioremediation procedures, and a rapid and efficient method to evaluate the potential toxic impact is required.

Bacterial whole-cell bioreporters have been developed in recent years. They have been found to be efficient, cost-effective, sensitive and selective to toxic materials. Therefore, specific whole-cell bioreporters were optimised and applied for accessing bioavailability and genotoxicity of particular toxins (van der Meer and Belkin, 2010). Significantly, they can be used in situ as a great alternative to complex, costly and labour intensive chemical analysis or animal tests. The whole-cell bioreporter ADPWH_recA uses a soil bacterium Acinetobacter baylyi ADP1 as the host, and has a chromosomal insertion of the promoterless lux CDABE cassette from Photorhabdus luminescens (Huang et al., 2005), which is controlled by the SOS-inducible recA promoter. The chromosomally based ADPWH_recA bioreporter can express bioluminescence in the presence of DNA damaging compounds. It has been applied in various studies to test the toxicity of a range of chemical com- 
pounds including polycyclic aromatic hydrocarbons and other groundwater contaminants (Song et al., 2009).

The toxicity of a compound is largely dependent on its concentration. Although the genotoxicity of $\mathrm{Cr}$ has been studied intensively, there are limited data using whole-cell bioreporters to indicate the toxicity of different $\mathrm{Cr}$ species at differing concentrations, and this is addressed in this study.

Monitoring the progress of soil and groundwater remediation is typically done by tracking of $\mathrm{Cr}(\mathrm{VI})$ concentrations over the remediation site. However, the decrease of $\mathrm{Cr}(\mathrm{VI})$ concentrations can be caused by various factors, such as dilution in groundwater and adsorption on soil particles, as well as by bioreduction. Knowing the mechanisms of how $\mathrm{Cr}(\mathrm{VI})$ concentration decreases is useful to help estimate the long term effect of the remediation process on a particular site. To assess the effectiveness of remedial interventions of $\mathrm{Cr}(\mathrm{VI})$ contamination, and to better understand the mechanism of $\mathrm{Cr}(\mathrm{VI})$ reduction, a more efficient method that can identify which are the dominant processes is required. Such a technique involves monitoring Cr isotope fractionation (Zhang et al., 2018).

Chromium has 4 isotopes. Isotopic fractionations are represented by the ${ }^{53} \mathrm{Cr} /{ }^{52} \mathrm{Cr}$ ratio, which is generally reported as relative deviations from a standard (e.g. the NIST SRM 979) in parts per thousand (per mil or \%o):

$$
\delta^{53} \mathrm{Cr}=\left[\frac{\left({ }^{53} \mathrm{Cr} /{ }^{52} \mathrm{Cr}\right)_{\text {sample }}}{\left({ }^{53} \mathrm{Cr} /{ }^{52} \mathrm{Cr}\right)_{\text {standard }}}-1\right] \times 1000
$$

The lighter isotopes have lower dissociation energy. Therefore, one common feature in many redox reactions is that the lighter isotopes are more reactive and so when $\mathrm{Cr}$ is partitioned between two species, the products will have lower $\delta^{53} \mathrm{Cr}$ values, and the remaining reactants higher values. This has been observed in many previous studies (Basu and Johnson, 2012, Kitchen et al., 2012, Zink et al., 2010). Elevated $\delta^{53} \mathrm{Cr}$ values in $\mathrm{Cr}(\mathrm{VI})$ therefore provide evidence that some $\mathrm{Cr}(\mathrm{VI})$ has been reduced, and can be employed to signal the extent of $\mathrm{Cr}(\mathrm{VI})$ reduction (Ellis et al., 2002).

In microbial $\mathrm{Cr}(\mathrm{VI})$ reduction processes, microbes progressively reduce dissolved $\mathrm{Cr}(\mathrm{VI})$ to insoluble $\mathrm{Cr}(\mathrm{III})$, preferentially removing lighter isotopes from the dissolved phase (Basu et al., 2014, Sikora et al., 2008), and the products never re-equilibrates with the original reactants. Since 
the lighter isotopes of $\mathrm{Cr}$ are enriched in the products, they will be progressively depleted in the original $\mathrm{Cr}(\mathrm{VI})$ pool. In this case, the isotope composition of the remaining $\mathrm{Cr}(\mathrm{VI})$ is related to the degree of depletion according to the Rayleigh equation (Rayleigh, 1896).

$$
R_{C r(V I)}=R_{C r(V I)}^{0} f^{\alpha-1}
$$

where $\mathrm{R}_{C r(V I)}$ is the ${ }^{53} \mathrm{Cr}$ ratio in the remaining $\mathrm{Cr}(\mathrm{VI}), \mathrm{R}_{C r(V I)}^{0}$ is that in the original $\mathrm{Cr}(\mathrm{VI})$ pool, $\alpha$ is the isotope fractionation factor, where $\alpha=\left({ }^{53} \mathrm{Cr} /{ }^{52} \mathrm{Cr}\right)_{C r(I I I)} /\left({ }^{53} \mathrm{Cr} /{ }^{52} \mathrm{Cr}\right)_{\operatorname{Cr}(V I)}$, and $\mathrm{f}$ is the fraction of the $\mathrm{Cr}(\mathrm{VI})$ that remains after reduction.

To quantitatively relate $\mathrm{Cr}$ isotope variations with the extent of reduction, information about the mechanisms of $\mathrm{Cr}$ isotope fractionation and the associate fractionation factors is required. During the past decade, attempts have been made to use Cr isotope data to help better understand the intrinsic-attenuation of $\mathrm{Cr}(\mathrm{VI})$ contaminated groundwater in some industrial sites, and the $\mathrm{Cr}(\mathrm{VI})$ concentration were found to vary greatly on different sites (Novak et al., 2017, 2018). The toxicity of $\mathrm{Cr}(\mathrm{VI})$ largely depends on its concentration, and different levels of $\mathrm{Cr}(\mathrm{VI})$ toxicity may affect the effectiveness of microbial metabolic activity in the environment. Thus, in order to better estimate the extent of intrinsic $\mathrm{Cr}(\mathrm{VI})$ reduction, the dependence between $\mathrm{Cr}(\mathrm{VI})$ concentration and microbial reduction fractionation factors must be established. However, the impact of different $\mathrm{Cr}(\mathrm{VI})$ initial concentrations and the associated toxicity of $\mathrm{Cr}(\mathrm{VI})$ on bacterial Cr isotope fractionation has not yet been studied, although our previous study has identified the relationships between several other important environmental conditions and $\mathrm{Cr}$ isotope signatures (Zhang et al., 2018, 2019). Therefore, this study focuses on determining the levels of Cr toxicity and their impact on $\mathrm{Cr}$ isotope fractionation by bacteria. For that purpose, a whole-cell bioreporter was used to indicate the toxicity of different species of $\mathrm{Cr}$ over a range of concentrations, and $\mathrm{Cr}$ isotope fractionation factors generated by bacterial $\mathrm{Cr}(\mathrm{VI})$ reduction were determined at different initial concentrations. We demonstrate that, for the first time, these two techniques are useful in monitoring bioremediation processes in the environments where $\mathrm{Cr}(\mathrm{VI})$ concentrations may reach levels that are toxic, and can be implemented to the remediation industries. 


\section{Materials and methods}

\subsection{Chromium toxicity tests}

To determine the appropriate range of $\mathrm{Cr}$ initial concentrations for bacterial reduction experiments, a chromium toxicity test was done by using the whole-cell bioreporter, Acinetobacter baylyi ADPWH_recA. This whole-cell bioreporter can generate bioluminescence in the presence of DNAdamaging compounds, and the level of bioluminescence generated can be monitored and related to the degree of toxicity. In the toxicity tests, the whole-cell bioreporter was cultured in the presence of different species of $\mathrm{Cr}$ with different initial concentrations. The growth and bioluminescence of the bioreporters in different groups were monitored temporally over the duration of the experiment. The level of Cr toxicity was then determined by comparing the growth rates and bioluminescent generation with those of the control group. All experiments were carried out in triplicate.

\subsubsection{Preparation of the bioreporter}

All chemicals used in this study were analytical-grade reagents (Sigma-Aldrich, USA). LB medium (Luria-Bertani medium) and LBK medium (LB medium with $10 \mu \mathrm{g}$ kanamycin $\mathrm{mL}^{-1}$ ) were used for cultivation of the strain and induction studies.

The strain was first recovered from $-80{ }^{\circ} \mathrm{C}$ and incubated on LB agar plate (supplemented with $10 \mu \mathrm{g}$ kanamycin $\mathrm{mL}^{-1}$ ) at $30^{\circ} \mathrm{C}$ overnight. One colony was then transferred and incubated in $5 \mathrm{~mL}$ LBK medium in a shaking incubator at $150 \mathrm{rpm}, 30^{\circ} \mathrm{C}$, for $12-14$ hours. Before the experiments, the strain was harvested by centrifugation at $4000 \mathrm{rpm}$ for 20 minutes. The cells were then re-suspended in $5 \mathrm{~mL}$ fresh $\mathrm{LB}$ medium and diluted by a factor of 10 with fresh LB medium for the experiments.

\subsubsection{Chromium sample preparation}

Potassium dichromate, potassium chromate and chromium chloride solutions with concentrations of 50, 200, 400 and $1000 \mathrm{mg}$ chromium/L were prepared. Milli-Q water $(\geq 18.2 \mathrm{M} \Omega \mathrm{cm})$ was used in one group as a control blank, and Mitomycin C (MMC) from Streptomyces caespitosus was used as a positive control in the experiment. 


\subsubsection{Bioreporter response measurements}

Aliquots of $180 \mu \mathrm{L}$ ADPWH_recA and $20 \mu \mathrm{L}$ of the different chromium solutions were transferred to, and mixed in, a 96-well microplate (black with clear bottom, Greiner, Germany), so that there were wells with concentrations of $0,5,20,40$ and $100 \mathrm{mg} / \mathrm{L}$ for each of the three different chromium solutions. In addition, Milli-Q water and mitomycin $\mathrm{C}(1 \mu \mathrm{M})$ were used for the negative and positive controls. Bioluminescent intensities and optical densities were both measured with a Bio-tek Synergy 2 HT plate reader every 30 minutes at $30{ }^{\circ} \mathrm{C}$ over 6 hours. Each group in this experiment contained triplicate samples and every measurement was done three times.

The intensity of bioluminescence expressed by the control group was taken to be the baseline. The toxicity of $\mathrm{Cr}$ was evaluated using an induction ratio, which can be calculated using the following equation:

$$
\text { The induction ratio }=\frac{\text { Bioluminescent intensity } \text { Cr treated group }}{\text { Bioluminescent intensity } \text { The negtive control }}
$$

The detection limit is defined as the lowest concentration of $\mathrm{Cr}(\mathrm{VI})$ causing a significant induction ratio response relative to the negative control $(p<0.01)$.

In the presence of DNA damaging compounds that are genotoxic to cells, cause the intensity of bioluminescence to increase with the rise in toxicity. In this case, the induction ratio is greater than 1 . However, when the toxicity level is exceeded so that cell functions are seriously damaged, the bioluminescence will decrease, and in this case, the induction ratio is less than 1 .

\section{2. $C r$ reduction experiments}

Cr reduction experiments were conducted with Pseudomonas fluorescens LB 300. LB (Luria Bertani) Broth (Sigma Aldrich) and Minimal salts medium (0.03g NH $4 \mathrm{Cl}, 0.03 \mathrm{~g} \mathrm{~K} \mathrm{HPO}_{4}, 0.05 \mathrm{~g}$ $\mathrm{KH}_{2} \mathrm{PO}_{4}, 0.01 \mathrm{~g} \mathrm{NaCl}$ and $0.01 \mathrm{~g} \mathrm{MgSO}_{4}$ in $1 \mathrm{~L}$ of Milli-Q water) were used in the study. Prior to the experiments, bacteria were cultured by transferring a single colony grown aerobically in a Petri dish containing LB Agar to a 1 L flask containing LB medium and then incubated at $30{ }^{\circ} \mathrm{C}$ and $120 \mathrm{rpm}$ overnight. To compensate for the variability of microbial systems, all experiments in this study were also done in triplicate. 
The aerobic reduction experiments were conducted in $150 \mathrm{~mL}$ Erlenmeyer flasks. When cell growth reached the late exponential phase, they were collected by centrifugation at $4100 \mathrm{rpm}$ and $4{ }^{\circ} \mathrm{C}$ for 20 minutes. The cells were then washed 3-4 times using $0.9 \%$ sterile $\mathrm{NaCl}$ solution before being added to $50 \mathrm{~mL}$ of fresh minimal salts medium. The cell density was monitored by using optical density (OD600) and plating, and was adjusted to $10^{9}-10^{10} / \mathrm{mL}$ in the experiment. Glucose was used as the electron donor in the study, and a glucose solution was sterilised by passing through a $0.22 \mu \mathrm{m}$ membrane filter. A Cr (VI) solution was prepared by dissolving potassium di-chromate in sterilized Milli-Q water and filtered through a $0.22 \mu \mathrm{m}$ membrane before the experiments. The media were then incubated at $30{ }^{\circ} \mathrm{C}$ and $120 \mathrm{rpm}$.

During the experiments, Cr(VI) was reduced by the bacteria aerobically, and Cr(III) produced. Periodically, aliquots of $1 \mathrm{~mL}$ were taken and centrifuged at $9000 \mathrm{rpm}$ at $4^{\circ} \mathrm{C}$ for $10 \mathrm{~min}$. The supernatant was filtered $(0.22 \mu \mathrm{m})$ and then transferred to a clean Eppendorf tube and stored at $-80^{\circ} \mathrm{C}$ before further treatment. $\mathrm{Cr}(\mathrm{VI})$ concentrations were measured by HPLC (Thermo Scienctific $^{T M}$ Dionex $^{T M}$ ICS-3000) (Zhang et al., 2018).

\section{3. $C r$ isotope measurement}

Cr isotopes were measured by a thermal ionization mass spectrometer (TIMS, Thermo Finnegan Triton). During the reduction experiments and the sample treatment period, isotope exchange between $\mathrm{Cr}(\mathrm{VI})$ and $\mathrm{Cr}(\mathrm{III})$ species was ignored, because equilibrium fractionation factors between Cr species were found to be negligible under these conditions (Wang et al., 2015, Zhang et al., 2018). The preparation method of samples for isotope composition determination largely followed that of Zhang et al. (2018). A double isotope spike method was employed for correction of isotopic fractionation during sample preparation and mass spectrometry. The data acquisition method is modified from Trinquier et al. (2008) and Zhang et al. (2018).

\section{Results}

\subsection{Determination of Cr toxicity}

The growth curves of $\mathrm{ADPWH}_{-} r e c \mathrm{~A}$ induced by different concentrations of $\mathrm{Cr}_{2} \mathrm{O}_{7}^{2-}, \mathrm{CrO}_{4}^{2-}$ and $\mathrm{Cr}(\mathrm{III})$ are shown in Figure 1. 
The relative cell numbers at each time were determined by measuring the optical density of each group at $600 \mathrm{~nm}$ wavelength (OD600), which is proportional related to cell number. Data for experiments with $\mathrm{Cr}(\mathrm{VI})$ are in Fig. 1A-1B. Compared with the control group, which only contained the bacteria in LB medium, the growth rates from all groups containing $\mathrm{Cr}(\mathrm{VI})$, regardless of the species, were much slower, demonstrating that $\mathrm{Cr}(\mathrm{VI})$ inhibited the growth of ADPWH_recA. Growth rates were found to be lower when $\mathrm{Cr}(\mathrm{VI})$ concentrations were higher, indicating a greater inhibition with increasing concentration.

The growth curves of ADPWH_recA from groups with different concentrations of $\mathrm{Cr}(\mathrm{III})$ are shown in Figure 1C, and were found to be close to one another. The slightly higher initial OD values for groups at high concentrations of $\mathrm{Cr}$ (III) $(>20 \mathrm{mg} / \mathrm{L})$ were due to the colour of $\mathrm{Cr}(\mathrm{III})$ species. No significant differences were observed between the control group and $\mathrm{Cr}$ (III)-treated groups at all time points $(p>0.05)$, indicating that $\mathrm{Cr}(\mathrm{III})$ concentrations have little impact on bacterial growth under the concentrations investigated in this study.

The induction ratios (IR) for ADPWH_recA over 6 hours of exposure to different species of chromium in the liquid phase are shown in Fig 2. In the experiments, $5 \mathrm{mg} / \mathrm{L}$ of $\mathrm{Cr}(\mathrm{VI})$ in liquid phase significantly induced bioluminescence of the bioreporter (IR $>1, p<0.05$ ), indicating that $\mathrm{Cr}(\mathrm{VI})$ induced genotoxicity (Fig 2A and Fig 2B). Another experiment with low $\mathrm{Cr}$ concentrations was done to confirm the sensitivity of the bioreporter, and it was shown that low levels of $\mathrm{Cr}$ $(<1 \mathrm{mg} / \mathrm{L})$ do not have a significant impact on bacterial growth (Fig 1D and Fig 1E), and the induction ratio is proportional to the dose (Fig 2D and Fig 2E). However, higher concentrations of $\mathrm{Cr}(\mathrm{VI})$ from both $\mathrm{Cr}_{2} \mathrm{O}_{7}^{2-}$ and $\mathrm{CrO}_{4}^{2-}$ showed greater bioluminescence inhibition of ADPWH_recA, and therefore decreased dose response curves with $\mathrm{Cr}(\mathrm{VI})$ concentrations (Fig 3A and Fig 3B). Compared to the control group, the bioluminescence from both groups with $100 \mathrm{mg} / \mathrm{L} \mathrm{Cr}(\mathrm{VI})$ were suppressed from the beginning of the experiment $(\mathrm{IR}<1)$, and the induction ratios to the control group decreased over the experimental period (Fig 2A and Fig 2B), suggesting that the vital functions of the bacteria were severely damaged. Compared with $\mathrm{Cr}_{2} \mathrm{O}_{7}^{2-}, \mathrm{CrO}_{4}^{2-}$ shows greater inhibition of bioluminescence with the same concentration of $\mathrm{Cr}(\mathrm{VI})$, indicating $\mathrm{CrO}_{4}^{2-}$ may be more toxic to ADPWH_rec A than $\mathrm{Cr}_{2} \mathrm{O}_{7}^{2-}$. We note that the species of $\mathrm{Cr}(\mathrm{VI})$ is dependent upon 
$\mathrm{pH}$ of the solution and the $\mathrm{Cr}(\mathrm{VI})$ concentration under aerobic conditions (Tandon et al., 1984).

The species reported in this study were the initial $\mathrm{Cr}(\mathrm{VI})$ salts used to make the stock solution. When dissolved in water, thermodynamic data suggest that chromate should become the dominant species, although at the $\mathrm{pH}$ of this experiments, chromate, dichromate, and hydrogen chromate will co-exist in solution (Fig. S1).

In the experiment with $\mathrm{Cr}(\mathrm{III})$, although bacteria growth rates remained the same as that of the control (Fig 1C), the IR values of the groups with 20, 40 and $100 \mathrm{mg} / \mathrm{L} \mathrm{Cr}$ (III) demonstrated mild inhibition of bioluminescence in the beginning, but the induction ratio increased over the experimental period and bioluminescence has been induced for all concentrations of $\mathrm{Cr}$ (III) (Fig 2C). The dose response curve revealed that higher Cr(III) concentration could cause greater induction of the bioluminescence (Fig 3C) with time, indicating $\mathrm{Cr}$ (III) was genotoxic at high concentrations.

\subsection{Bacterial $\operatorname{Cr}(V I)$ reduction experiments}

Cr reduction experiments by Pseudomonas fluorescens LB300 were conducted over a concentration range of 5 to $40 \mathrm{mg} / \mathrm{L} \mathrm{Cr}\left(\mathrm{VI}\right.$ ) (initial form of $\mathrm{Cr}_{2} \mathrm{O}_{7}^{2-}$ ), with the fastest reduction rate occuring within the first 24 hours (Fig. 4A). After that point, the reduction rate slowed down. About $50 \% \mathrm{Cr}(\mathrm{VI})$ was reduced in the groups containing $40 \mathrm{mg} / \mathrm{L}$ and $20 \mathrm{mg} / \mathrm{L} \mathrm{Cr}(\mathrm{VI})$, initially. Essentially, complete $\mathrm{Cr}(\mathrm{VI})$ reduction was only observed in the experimental group initially containing $5 \mathrm{mg} / \mathrm{L} \mathrm{Cr}(\mathrm{VI})$. The reduction rates of $\mathrm{Cr}(\mathrm{VI})$ were found to be faster at higher initial $\mathrm{Cr}(\mathrm{VI})$ concentrations (Fig. 4A), reflecting the adaptation of the bacteria to the toxic conditions in this study.

\subsection{The application of $\mathrm{Cr}$ isotopes}

The isotope data are presented in Fig. 4B, and are compared with published data (Zhang et al., 2018, 2019). The data shown as circle, triangle and square are collected in experiments under exactly the same conditions apart from initial $\mathrm{Cr}(\mathrm{VI})$ concentrations, while the data shown as cross are collected in experiments where some conditions are slightly different (eg. pH, Zhang et al. $(2018,2019))$. With the reduction of $\mathrm{Cr}(\mathrm{VI})$, the $\delta^{53} \mathrm{Cr}$ value increased, indicating the produced Cr(III) had a lighter isotopic composition. 
Cr (VI) reduction experiments in this study were conducted in a well-mixed, closed environment, in which the isotopic fractionation factor, $\alpha$, is consistent with time. In this case, the $\delta^{53} \mathrm{Cr}$ value of the remaining $\mathrm{Cr}(\mathrm{VI})$ in the system evolves according to the Rayleigh relationship (Eq. 2).

The best fit $\alpha$ values can be found by plotting the linearised equation and using linear regression for the plots (Kitchen et al., 2012). Uncertainties can be calculated as $2 \times$ standard errors of the best fit slopes.

The results were expressed as $\varepsilon$.

$$
\varepsilon \approx(\alpha-1) \times 1000 \%
$$

The fractionation factor $\varepsilon$ was $-3.1 \pm 0.3 \%$ for all groups with various initial $\mathrm{Cr}(\mathrm{VI})$ concentrations, indicating that different initial $\mathrm{Cr}(\mathrm{VI})$ concentrations and the associated toxicity did not have a noticeable impact on bacterial $\mathrm{Cr}$ isotope fractionations.

\section{Discussion}

\subsection{Monitoring Cr toxicity}

Previous studies have demonstrated that $\mathrm{Cr}(\mathrm{VI})$ can cause cellular oxidative stress and defence against its toxicity centres on activation of antioxidant mechanisms (Ackerley et al., 2006). Its toxicity towards microorganisms can change community structure and function and their metabolic activity, and therefore leads to the selection of $\mathrm{Cr}(\mathrm{VI})$ resistance and inhibition of the biodegradation of other organic pollutants (Kourtev et al., 2006). Different microbes have variable resistance to Cr toxicity; for example, Pseudomonas strains were found to be able to resist up to around 200 mg $\mathrm{Cr}(\mathrm{VI})$, but the cyanobacterial group was found to be much more sensitive to chromium (Viti et al., 2006).

Similar to the finding in our study, $\mathrm{Cr}(\mathrm{VI})$ is generally more toxic than $\mathrm{Cr}(\mathrm{III})$. Indeed, $\mathrm{Cr}(\mathrm{III})$ is cationic and readily retained by the soil's cation exchange complex, while $\mathrm{Cr}(\mathrm{VI})$ occurs as an anion and is more soluble and mobile in the environment. Therefore, $\mathrm{Cr}(\mathrm{VI})$ is more likely to be taken up by soil bacteria and thus more harmful. Moreover, $\mathrm{Cr}(\mathrm{VI})$ is more effective at penetrating cellular 
membranes than $\mathrm{Cr}(\mathrm{III})$, and in the process induces oxidative stress that causes cell membrane damage. There are reports that $\mathrm{Cr}(\mathrm{VI})$ can be transported through mammalian cell membranes by the carboxylate, sulphate and phosphate carrier systems (Bopp and Ehrlich, 1988, Michel et al., 2003). When $\mathrm{Cr}(\mathrm{VI})$ enters into cells, it reacts spontaneously with the intracellular reductants and generates short lived intermediates $\mathrm{Cr}(\mathrm{V})$ and/or $\mathrm{Cr}(\mathrm{IV})$ that can be ultimately converted to $\mathrm{Cr}(\mathrm{III})$ in cells (Xu et al., 2004, 2005). In the cytoplasm, some of the $\mathrm{Cr}(\mathrm{V})$ that is generated can be re-oxidised to $\mathrm{Cr}(\mathrm{VI})$ and production of reactive oxygen species (ROS) that can easily combine with DNA-protein complexes; $\mathrm{Cr}(\mathrm{IV})$ is able to bind to cellular material, altering their physiological functions.

Although there are many studies concerning the toxicity of $\mathrm{Cr}(\mathrm{VI})$, few have used the whole-cell bioreporters to assess its toxicity with respect to different $\mathrm{Cr}$ species and concentrations. Among the known whole-cell bioreporters, E.coli based system has been the most utilised (Ackerley et al., 2006, Llagostera et al., 1986). However, it is not ideal for genotoxicity assessments in natural environments, since it is actually a gut-derived organism. Instead, the whole-cell bioreporter ADPWH_recA is developted from Acinetobacter baylyi ADP1, which is a soil-derived bacterium, since it is more appropriate for assessing ambient environments. It has been demonstrated to be very sensitive, specific (to DNA damage), and robust in various environments. Moreover, it is able to detect not only genotoxicity but also cytotoxicity, both qualitatively and quantitatively, and has been successfully applied in various studies testing a variety of toxic chemical compounds (Song et al., 2009).

The chromosomally based ADPWH_recA bioreporter can express bioluminescence in the presence of DNA damaging compounds. In the toxicity assessment in this study, low concentrations (5 mg/L) of $\mathrm{Cr}(\mathrm{VI})$ were found to induce the intensity of biolumenescence, whilst higher concentrations $(20,40$ and $100 \mathrm{mg} / \mathrm{L})$ decreased it, indicating that such high concentrations of $\mathrm{Cr}(\mathrm{VI})$ inhibited cell metabolism and exceeded the cellular DNA repair capability. Similar observations were made with mitomycin $\mathrm{C}(\mathrm{MMC})$, which damages DNA by cross-linking DNA or protein (Song et al., 2009). In previous studies, it was found that greater concentrations of MMC induced a higher intensity of bioluminescence until the concentration was over $3 \mu \mathrm{M}$, when bioluminescence 
induction then decreased (Song et al., 2009, 2014).

The induction ratios (IR, Eq. 3) at the end of the experiments are shown in Fig 3. The dose response curve clearly shows that higher $\mathrm{Cr}(\mathrm{VI})$ concentration caused greater inhibition to the generation of bioluminescence by the bacteria. In the presence of genotoxins, ADPWH_recA can be induced to express bioluminescence and the induction ratio of which is usually proportional to the dose, but in this study, the bioluminescence was clearly inhibited by higher concentrations of $\mathrm{Cr}(\mathrm{VI})$, which indicates that inhibition was caused by cytotoxicity of $\mathrm{Cr}(\mathrm{VI})$ rather than genotoxicity. Song et al. (2014) also observed that Cr(VI) could inhibit the bioluminescence of another Acinetobacter baylyi based light-off bioreporter when the dose exceeded 5200ng/assay (26mg/L). In our study, the induction ratio for groups with 20 and $40 \mathrm{mg} / \mathrm{L} \mathrm{Cr}(\mathrm{VI})$ were calculated to be between 0.8 to 1.2 , which is caused by the combination of both bioluminescence induction and inhibition of the growth. It can be concluded from the results that $\mathrm{Cr}(\mathrm{VI})$ is both genotoxic and cytotoxic depending on the dose level.

Although the $\mathrm{Cr}(\mathrm{VI})$ toxicity experiments were conducted at approximately the same pH conditions, the initial form of $\mathrm{Cr}(\mathrm{VI})$ added into the system may have slightly altered the $\mathrm{pH}$ and resulted in a different equilibrium mixture of $\mathrm{Cr}(\mathrm{VI})$ species in solution (Fig. S1). Of the two initial forms of $\mathrm{Cr}(\mathrm{VI})$ species, $\mathrm{CrO}_{4}^{2-}$ was found to be slightly more toxic to the bioreporter, especially at the highest concentration $(100 \mathrm{mg} / \mathrm{L})$. However, this result is at odds with the results of the study by Francisco et al. (2010), where dichromate was found to be more toxic than chromate at pH 7.2, to a chromium resistant and reducing strain Ochrobactrum tritici 5bvl1. This may have been due to the difference in physiology between different species, especially between chromium resistant and non-resistant bacteria. A previous study indicated that the bioassay would be insensitive to $\mathrm{Cr}(\mathrm{VI})$ in either acute or chronic toxicity tests, if $\mathrm{Cr}(\mathrm{VI})$ reducing bacteria were used (Fulladosa et al., 2006). The bioreporter used in this study is Cr non-resistant bacteria.

After reduction, $\mathrm{Cr}(\mathrm{III})$ was produced. Although $\mathrm{Cr}(\mathrm{III})$ is required for normal sugar and fat metabolism, some studies showed it could also be toxic to microbes by causing DNA damage (Plaper et al., 2002) or by changing the $\mathrm{pH}$ (Garcia et al., 1994) in the surrounding environment. Intracellular studies indicated that Cr(III)-DNA adducts and related hydroxyl radical oxidative 
DNA damage have a central role in originating the genotoxicity. In this study, the toxicity of $\mathrm{Cr}(\mathrm{III})$ was also assessed and demonstrated to be much lower than the toxicity of $\mathrm{Cr}(\mathrm{VI})$ for similar concentrations. However, although $\mathrm{Cr}(\mathrm{III})$ did not have a significant impact on bacterial growth $(p>0.5)$, the IR value increased with $\mathrm{Cr}(\mathrm{III})$ concentration, indicating it was genotoxic to the bioreporter, particularly at higher concentrations $(100 \mathrm{mg} / \mathrm{L})$. These results suggested that even if $\mathrm{Cr}(\mathrm{VI})$ was reduced to $\mathrm{Cr}(\mathrm{III})$, if the original concentration was too high, it may still cause significant problems in the environment, and therefore other techniques should be used to remove it.

Microbes used in bioremediation processes must have high resistance to the target compounds. For example, the bacteria used in the reduction experiments here is a species that can resist $\mathrm{Cr}$ toxicity to quite high concentrations (Wang and Xiao, 1995). However, to ensure the sensitivity of bioreporters, the strains used always have low tolerance to the toxic compounds. Therefore, if the $\mathrm{Cr}(\mathrm{VI})$ concentrations in a site do not exceed the level in which $\mathrm{Cr}(\mathrm{VI})$ can severely damage the bioreporter, bioremediation may be an option, where $\mathrm{Cr}(\mathrm{VI})$ resistant bacteria are generally used. However, if the bioreporter is severely damaged or killed by the toxins in a contaminated site, other physical or chemical remediation methods should be planned instead of using biological remediation methods.

\subsection{Insight from $\mathrm{Cr}$ isotopes}

Cr isotope variations were demonstrated to be a good indicators of microbial $\mathrm{Cr}(\mathrm{VI})$ reduction processes. Various bacteria are reported to be able to reduce $\mathrm{Cr}(\mathrm{VI})$, and the associated isotope fractionation factors have been determined (Basu and Johnson, 2012, Sikora et al., 2008, Zhang et al., 2018), with $\epsilon$ values ranging between $-1.5 \%$ to $-5.0 \%$ and a mean value of $-3.3 \%$ (Zhang et al., 2018). The impact of a series of different environmental parameters on microbial $\mathrm{Cr}(\mathrm{VI})$ reduction and isotope fractionation has been assessed in previous studies (Zhang et al., 2018). This confirmed that changes in $\mathrm{pH}$ and electron donor concentration did not have any detectable impact on microbial $\mathrm{Cr}$ isotope fractionation; however, the fractionation factor does depend upon microbial species and respiration pathways, the type of electron donors, and the presence of some specific minerals (Zhang et al., 2018). Cr concentrations in the natural and contaminated environment vary 
widely, and so any dependence between this and microbial reduction fractionation factors must be established. Cr concentrations are typically between 25 to $5000 \mathrm{ng} / \mathrm{L}$ in rivers and lakes, and is about 5 to $900 \mathrm{ng} / \mathrm{L}$ in sea waters (Bradl, 2005). In Cr contaminated sites, the concentration can be as high as $30 \mathrm{mg} / \mathrm{L}$ (Stewart et al., 2007, 2010) or even higher (Pinon-Castillo et al., 2010).

Similar to the results in study, Wang and Shen (1995) also found greater reduction rates at higher initial concentrations of $\mathrm{Cr}(\mathrm{VI})$ by Pseudomonas, and this observation may reflect the bacteria adaptation to the toxicity. As shown in Figure 4, the $\mathrm{Cr}$ isotope fractionation factors for $\mathrm{Cr}(\mathrm{VI})$ reduction with different $\mathrm{Cr}$ concentrations are indistinguishable from on another. The toxicities of $\mathrm{Cr}(\mathrm{VI})$ at these different concentrations therefore did not have great impact on the microbial mediated Cr isotope fractionation, and so a single fractionation factor can be used across an environment where $\mathrm{Cr}$ concentration varies. Moreover, although the $\mathrm{Cr}(\mathrm{VI})$ species in the contaminated water can change with different $\mathrm{pH}$ and $\mathrm{Cr}(\mathrm{VI})$ concentrations, our previous study has demonstrated that varying $\mathrm{pH}$ values would not affect bacterial $\mathrm{Cr}$ isotope fractionation factors, and therefore, along with the results in this study, we can conclude that the speciation of $\mathrm{Cr}(\mathrm{VI})$ and its toxicity do not impact bacterial $\mathrm{Cr}$ isotope fractionations. This suggests that $\mathrm{Cr}$ isotope techniques can be applied in monitoring the bioreduction processes for site remediation at varies $\mathrm{pH}$ and $\mathrm{Cr}(\mathrm{VI})$ concentrations. However, since fractionation factors may be dependent on other conditions, such as which Cr-reducing bacteria species or mineral compositions are present, the determination of site-specific fractionation factors may be necessary to more tightly link isotope variations with the extent of $\mathrm{Cr}(\mathrm{VI})$ reduction (Zhang et al., 2018, 2019). Nonetheless, Cr isotope variations are generally useful and can be used to estimate the extent of depletion occurred.

\subsection{General scope of the two techniques}

To remediate Cr-contaminated water and soils, the initial stages are often accomplished in a relatively short time by removing contaminant sources, and highly contaminated shallow soils, or installing low permeability caps. After that, remediation of the subsurface may take much longer and be costly. Common strategies for Cr remediation include the no action option, pump-andtreat remediation, soil solidification/stabilization, and bioremediation (Jeyasingh and Philip, 2005, Palmer and Wittbrodt, 1991). 
To find the optimal remedial strategies for the contaminated sites, some understanding of the physical and chemical processes affecting the migration and chemical state of $\mathrm{Cr}$ is significant advantage. For example, advection, dispersion, and diffusion are physical processes affecting the rate at which $\mathrm{Cr}$ can migrate in the subsurface. Redox reactions, chemical speciation, adsorption/desorption phenomena, and precipitation/dissolution reactions can control the transformation and mobility of $\mathrm{Cr}$. Cr isotope variations are shown to have potential to be diagnostic of specific processes (Basu and Johnson, 2012, Ellis et al., 2002, 2004, Kitchen et al., 2012), and such information have direct implications in the design of the remedial system. For example, Cr-contaminated groundwater could be remediated by passing through an engineered geochemical barrier, which contains a material that reacts with the $\mathrm{Cr}$ to enhance its removal. Ideally, such barrier should promote the reduction of $\mathrm{Cr}(\mathrm{VI})$ and the precipitation of $\mathrm{Cr}(\mathrm{III})$. However, some materials in the barrier may also adsorb $\mathrm{Cr}(\mathrm{VI})$. Adsorption reactions can only retard the rate of $\mathrm{Cr}(\mathrm{VI})$ through the barrier; it cannot prevent the migration of $\mathrm{Cr}(\mathrm{VI})$. Therefore, it is useful to distinguish between the reduction and adsorption of $\mathrm{Cr}(\mathrm{VI})$, in order to better evaluate such a strategy. This can be easily done by measuring the variation of Cr isotopes (Ellis et al., 2002, 2004). Other examples may involve strategies such as the pump-and-treat method, which is one of the most commonly used methods for aquifer remediation. With this approach contaminated water is pumped to the surface and treated either on site or at treatment plant. By monitoring $\mathrm{Cr}$ isotopes from water in the extraction well, it may be possible to determine the reduction capacity along the flow path (Berna et al., 2010), or to tell whether any solid phase precipitates such as $\mathrm{CaCrO}_{4}$ and $\mathrm{BaCrO}_{4}$ have contributed to the $\mathrm{Cr}(\mathrm{VI})$ concentration by dissolution (Palmer and Wittbrodt, 1991). Such information is important to help determine the operation time for the pump-and-treat strategy, and to decide whether chemical enhancement should be added in the strategy.

For sites with relatively low concentration of $\mathrm{Cr}(\mathrm{VI})$, bioremediation may be another option. Such strategy deploys naturally occurring organisms to transform hazardous substances so they are less toxic, which can be applied both in situ and ex situ applications. The site can be examined by measuring the bioavailability and toxicity of $\mathrm{Cr}(\mathrm{VI})$ by microbial bioreporters; and secondly, by determining whether bioreduction is a more dominant process onsite. Many previous studies 
have demonstrated that the isotope signatures generated by abiotic reduction and biotic reduction are different (Ellis et al., 2002, Sikora et al., 2008, Zhang et al., 2018). By conducting site-specific analysis, it may be possible to determine whether intrinsic bioreduction has potential, or whether intervention is required to accelerate the process, for example by introducing more nutrients and oxygen to enhance remedial bioactivity. Our findings suggest that the $\mathrm{Cr}(\mathrm{VI})$ concentration does not impact on Cr isotope fractionation factors generated by microbes. This is an important observation, since Cr stable isotopes ratios help to elucidate the mechanism by which bioremediation is occurring. This information can be exploited to stimulate rates of bioremediation even further.

\section{Conclusions}

We employed a novel combination of techniques in this study, where the toxicity of different species of $\mathrm{Cr}$ was assessed using a whole-cell bioreporter ADPWH_recA over a wide range of concentrations, and the impact of $\mathrm{Cr}(\mathrm{VI})$ toxicity on microbial $\mathrm{Cr}$ reduction and isotope fractionation was evaluated. Two significant findings were made in this study: 1) The bioreporter was found to be sensitive to the concentrations of both $\mathrm{Cr}(\mathrm{VI})$ and $\mathrm{Cr}(\mathrm{III})$. It successfully provided a measure of genotoxicity of $\mathrm{Cr}(\mathrm{VI})$ at low $(<5 \mathrm{mg} / \mathrm{L})$ and cyto-toxicity at high concentrations. $\mathrm{Cr}(\mathrm{III})$ was found to be genotoxic, especially at the highest concentration (100mg/L). 2)The isotopic fractionation factors obtained from the reduction experiments were insensitive to different initial $\mathrm{Cr}$ concentrations, indicating bacteria use a similar reduction mechanism under these conditions, and therefore the isotope technique can be applied in monitoring the bioremediation process in different stages, since the change in isotope ratios can be used to estimate the extent of $\mathrm{Cr}$ reduction at sites with different Cr concentrations.

The study demonstrated that the whole-cell bioreporter ADPWH_recA and Cr isotope technique can be combined to first indicate the toxicity of the bioavailable $\mathrm{Cr}$ and provide further information to plan a remediation strategy. Secondly, bacterial Cr isotope fractionation factor does not change with initial Cr concentrations, which simplifies the monitoring of depletion, since a change of isotope fractionation factors would indicate a change in reduction mechanism. Therefore, assessment of the isotopic fractionations provided unique insight into the underlying processes 
459

460

461

462

463

464

driving the bioremediation process and thus provided opportunities to manipulate and enhance the process to accelerate even further.

\section{Acknowledgements}

This work was supported by the EU Framework 7 Marie Curie Initial Training Network MetTrans. We thank Prof. Yi-Tin Wang and Dr. Bo Fisher (University of Washington) for sending us the bacteria strain Pseudomonas fluorescens LB300. 


\section{References}

Ackerley, D. F., C. F. Gonzalez, M. Keyhan, R. Blake, and A. Matin (2004), Mechanism of chromate reduction by the Escherichia coli protein, NfsA, and the role of different chromate reductases in minimizing oxidative stress during chromate reduction, Environmental Microbiology, $6(8), 851-860$.

Ackerley, D. F., Y. Barak, S. V. Lynch, J. Curtin, and A. Matin (2006), Effect of chromate stress on escherichia coli k-12, Journal of Bacteriology, 188(9), 3371-3381.

Antonini, J. M., and J. R. Roberts (2007), Chromium in stainless steel welding fume suppresses lung defense responses against bacterial infection in rats, Journal of Immunotoxicology, 4(2), $117-127$.

Basu, A., and T. M. Johnson (2012), Determination of hexavalent chromium reduction using cr stable isotopes: Isotopic fractionation factors for permeable reactive barrier materials, Environmental Science $\& 3$ Technology, 46(10), 5353-5360.

Basu, A., T. M. Johnson, and R. A. Sanford (2014), Cr isotope fractionation factors for Cr(VI) reduction by a metabolically diverse group of bacteria, Geochimica et Cosmochimica Acta, 142(0), 349-361.

Berna, E. C., T. M. Johnson, R. S. Makdisi, and A. Basui (2010), Cr stable isotopes as indicators of $\mathrm{Cr}(\mathrm{VI})$ reduction in groundwater: A detailed time-series study of a point-source plume, Environmental Science 83 Technology, 44(3), 1043-1048.

Bopp, L., and H. Ehrlich (1988), Chromate resistance and reduction in pseudomonas fluorescens strain lb300, Archives of Microbiology, 150(5), 426-431.

Bradl, H. (2005), Heavy Metals in the Environment: Origin, Interaction and Remediation, Academic Press.

Dayan, A., and A. Paine (2001), Mechanisms of chromium toxicity, carcinogenicity and aller- 
genicity: Review of the literature from 1985 to 2000, Human and Experimental Toxicology, 20, 439-451.

Desai, C., K. Jain, and D. Madamwar (2008), Evaluation of in vitro Cr(VI) reduction potential in cytosolic extracts of three indigenous bacillus sp isolated from $\mathrm{Cr}(\mathrm{VI})$ polluted industrial landfill, Bioresource Technology, 99(14), 6059-6069.

Ellis, A. S., T. M. Johnson, and T. D. Bullen (2002), Chromium isotopes and the fate of hexavalent chromium in the environment, Science, 295(5562), 2060-2062.

Ellis, A. S., T. M. Johnson, and T. D. Bullen (2004), Using chromium stable isotope ratios to quantify $\mathrm{Cr}(\mathrm{VI})$ reduction: Lack of sorption effects, Environmental Science \& Technology, 38(13), 3604-3607.

Francisco, R., A. Moreno, and P. V. Morais (2010), Different physiological responses to chromate and dichromate in the chromium resistant and reducing strain ochrobactrum tritici 5bvl1, Biometals, 23, 713-725.

Fulladosa, E., V. Desjardin, J. C. Murat, R. Gourdon, and I. Villaescusa (2006), Cr(vi) reduction into $\mathrm{Cr}(\mathrm{III})$ as a mechanism to explain the low sensitivity of Vibrio fischeri bioassay to detect chromium pollution, Chemosphere, 65(4), 644-650.

Garcia, M. T., I. Ribosa, L. Perez, and J. S. Leal (1994), The environmental-impact of chromium salts - ecotoxicity and inhibition of surfactant biodegradation, Toxicological and Environmental Chemistry, $44(3-4), 225-232$.

Hossain, M. A., M. Alam, D. Yonge, and P. Dutta (2005), Finite element modeling of cr(vi) reduction by shewanella oneidensis mr-1 employing the dual-enzyme kinetic model, Computers 8 Geosciences, 31(10), 1286-1292.

Huang, W. E., H. Wang, H. Zheng, L. Huang, A. Singer, I. Thompson, and A. Whiteley (2005), Chromosomally located gene fusions constructed in Acinetobacter sp. ADP1 for the detection of salicylate, Environmental microbiology, \%, 1339-1348. 
Jeyasingh, J., and L. Philip (2005), Bioremediation of chromium contaminated soil: optimization of operating parameters under laboratory conditions, Journal of Hazardous Materials, 118(1-3), 113-120.

Kitchen, J. W., T. M. Johnson, T. D. Bullen, J. M. Zhu, and A. Raddatz (2012), Chromium isotope fractionation factors for reduction of $\mathrm{Cr}(\mathrm{VI})$ by aqueous $\mathrm{Fe}(\mathrm{II})$ and organic molecules, Geochimica Et Cosmochimica Acta, 89, 190-201.

Kourtev, P. S., C. H. Nakatsu, and A. Konopka (2006), Responses of the anaerobic bacterial community to addition of organic c in chromium(VI)- and iron(III)-amended microcosms, Applied and Environmental Microbiology, 72(1), 628-637.

Llagostera, M., S. Garrido, R. Guerrero, and J. Barbe (1986), Inducation of SOS genes of Escherichia coli by chromium compounds, Environmental mutagenesis, 8(4), 571-577.

Michel, C., M. T. Giudici-Orticoni, F. Baymann, and M. Bruschi (2003), Bioremediation of chromate by sulfate-reducing bacteria, cytochromes c3 and hydrogenases, Water Air and Soil Pollution, 3(3), 161-169.

Novak, M., E. Martinkova, V. Chrastny, M. Stepanova, O. Sebek, A. Andronikov, J. Curik, F. Veselovsky, E. Prechova, M. Houskova, F. Buzek, J. Farkas, and A. Komarek (2017), The fate of $\operatorname{cr}(\mathrm{VI})$ in contaminated aquifers 65 years after the first spillage of plating solutions: a delta cr-53 study at four central european sites., CATENA, 158, 371-380.

Novak, M., O. Sebek, V. Chrastny, L. Hellerich, A. Andronikov, E. Martinkova, J. Farkas, P. Pacherova, J. Curik, M. Stepanova, E. Prechova, M. Houskova, V. Zoulkova, F. Veselovsky, I. Svobodova, P. Janotova, and A. Komarek (2018), Comparison of $53 \operatorname{crcr}(v i)$ values of contaminated groundwater at two industrial sites in the eastern u.s. with contrasting availability of reducing agents., Chemical Geology, 481, 74-84.

Palmer, C. D., and P. R. Wittbrodt (1991), Processes affecting the remediation of chromiumcontaminated sites, Environmental Health Perspectives, 92, 25-40. 
Pan, X., Z. Liu, Z. Chen, Y. Cheng, D. Pan, J. Shao, Z. Lin, and X. Guan (2014), Investigation of $\mathrm{Cr}(\mathrm{VI})$ reduction and $\mathrm{Cr}(\mathrm{III})$ immobilization mechanism by planktonic cells and biofilms of bacillus subtilis ATCC-6633, Water Research, 55(0), 21-29.

Park, C. H., M. Keyhan, B. Wielinga, S. Fendorf, and A. Matin (2000), Purification to homogeneity and characterization of a novel pseudomonas putida chromate reductase, Applied and Environmental Microbiology, 66(5), 1788-1795.

Pinon-Castillo, H. A., E. M. S. Brito, M. Goni-Urriza, R. Guyoneaud, R. Duran, G. V. NevarezMoorillon, J. F. Gutierrez-Corona, C. A. Caretta, and G. E. Reyna-Lopez (2010), Hexavalent chromium reduction by bacterial consortia and pure strains from an alkaline industrial effluent, Journal of Applied Microbiology, $109(6), 2173-2182$.

Plaper, A., S. Jenko-Brinovec, A. Premzl, J. Kos, and P. Raspor (2002), Genotoxicity of trivalent chromium in bacterial cells. possible effects on DNA topology, Chemical Research in Toxicology, $15(7), 943-949$.

Ramirez-diaz, M., C. Diaz-Perez, E. Vargas, H. Riveros-Rosas, J. Campos-Garcia, and C. Cervantes (2008), Mechanisms of bacterial resistance to chromium compounds, Biometals, 21, 321-332.

Rayleigh, S. R. S. (1896), Theoretical considerations respecting the separation of gases by diffusion and similar processes, Philosophical Magazine Series 5, 42(259).

Sikora, E. R., T. M. Johnson, and T. D. Bullen (2008), Microbial mass-dependent fractionation of chromium isotopes, Geochimica Et Cosmochimica Acta, 72(15), 3631-3641.

Song, Y., G. Li, S. Thornton, L. P. Thompson, S. Banwart, and H. W. Lerner, D. N (2009), Optimization of bacterial whole cell bioreporters for toxicity assay of environmental samples, Environmental Science 86 Technology, 43, 7931-7938.

Song, Y., B. Jiang, S. Tian, H. Tang, Z. Liu, C. Li, J. Jia, W. E. Huang, X. Zhang, and G. Li (2014), A whole-cell bioreporter approach for the genotoxicity assessment of bioavailability of toxic compounds in contaminated soil in China, Environmental Pollution, 195, 178-184. 
Stewart, D. I., I. T. Burke, and R. Mortimer (2007), Stimulation of microbially mediated chromate reduction in alkaline soil-water systems, Geomicrobiology Journal, 24(7-8), 655-669.

Stewart, D. I., I. T. Burke, D. V. Hughes-Berry, and R. A. Whittleston (2010), Microbially mediated chromate reduction in soil contaminated by highly alkaline leachate from chromium containing waste, Ecological Engineering, 36(2), 211-221.

Tandon, R. K., P. T. Crisp, J. Ellis, and R. S. Baker (1984), Effect of pH on chromium(VI) species in solution, Talanta, $31(3), 227-228$.

Trinquier, A., J. L. Birck, and C. J. Allegre (2008), High-precision analysis of chromium isotopes in terrestrial and meteorite samples by thermal ionization mass spectrometry, Journal of Analytical Atomic Spectrometry, 23(12), 1565-1574.

van der Meer, J., and S. Belkin (2010), Where microbiology meets microengineering: design and applications of reporter bacteria, Nature Reviews Microbiology, 8, 511-522.

Viti, C., A. Mini, G. Ranalli, G. Lustrato, and L. Giovannetti (2006), Response of microbial communities to different doses of chromate in soil microcosms, Applied Soil Ecology, 34(2-3), $125-139$.

Wang, X., T. M. Johnson, and A. S. Ellis (2015), Equilibrium isotopic fractionation and isotopic exchange kinetics between $\mathrm{Cr}(\mathrm{III})$ and $\mathrm{Cr}(\mathrm{VI})$, Geochimica et Cosmochimica Acta, 153(0), 72 90.

Wang, Y. T., and H. Shen (1995), Bacterial reduction of hexavalent chromium, Journal of Industrial Microbiology, 14(2), 159-163.

Wang, Y.-T., and C. Xiao (1995), Factors affecting hexavalent chromium reduction in pure cultures of bacteria, Water Research, 29(11), 2467-2474.

Xu, X., H. Li, and J. Gu (2004), Reduction of hexavalent chromium by ascorbic acid in aqueous solutions., Chemos, 57, 609-613. 
Xu, X., H. Li, J. Gu, and X. Li (2005), Kinetics of the reduction of chromium (VI) by vitamin C., Environmental Toxicology and Chemistry, 24, 1310-1314.

Zhang, Q., L. Y. Yang, and W. Wang (2011), Bioaccumulation and trophic transfer of dioxins in marine copepods and fish, Environmental pollution, 159(12), 3390-3397.

Zhang, Q., K. Amor, S. J. G. Galer, I. Thompson, and D. Porcelli (2018), Variations of stable isotope fractionation during bacterial chromium reduction processes and their implications, Chemical geology, 481, 155-164.

Zhang, Q., K. Amor, S. J. G. Galer, I. Thompson, and D. Porcelli (2019), Using stable isotope fractionation factors to identify cr(vi) reduction pathways: Metal-mineral-microbe interactions, Water Research, 151, 98-109.

Zink, S., R. Schoenberg, and M. Staubwasser (2010), Isotopic fractionation and reaction kinetics between $\mathrm{Cr}(\mathrm{III})$ and $\mathrm{Cr}(\mathrm{VI})$ in aqueous media, Geochimica Et Cosmochimica Acta, 74(20), $5729-5745$. 

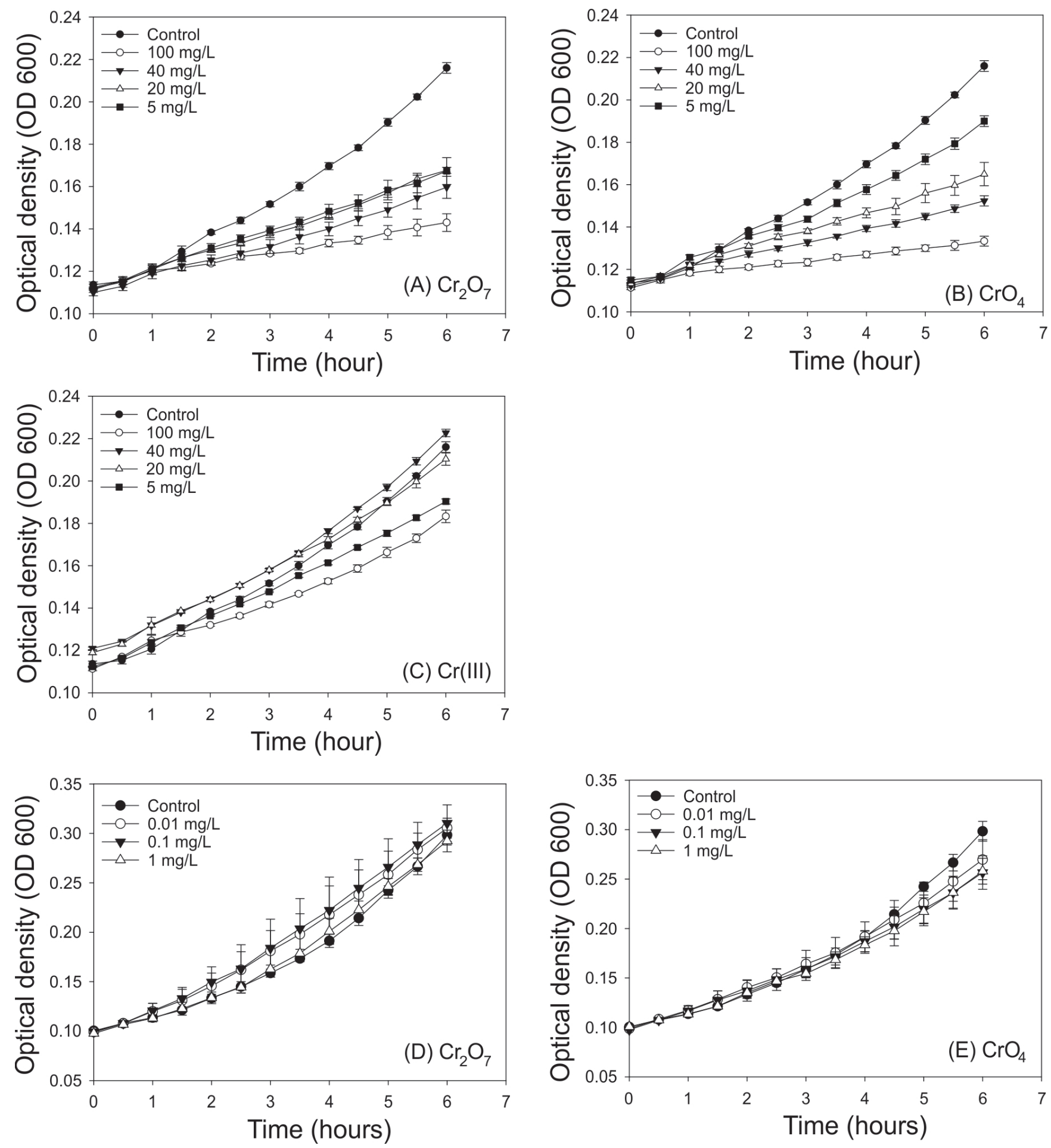

Figure 1: Growth curve of the $\mathrm{ADPWH}_{-} r e c \mathrm{~A}$ with different concentrations of $\mathrm{K}_{2} \mathrm{Cr}_{2} \mathrm{O}_{7}$ (A and D), $\mathrm{K}_{2} \mathrm{CrO}_{4}$ (B and E) and $\mathrm{Cr}(\mathrm{III})(\mathrm{C})$. Higher concentrations of $\mathrm{K}_{2} \mathrm{Cr}_{2} \mathrm{O}_{7}$ and $\mathrm{K}_{2} \mathrm{CrO}_{4}$ affected the growth of the ADPWH_rec A to a larger extent. There were no significant difference between each group at low $\mathrm{Cr}(\mathrm{VI})$ concentration levels $(<1$ $\mathrm{mg} / \mathrm{L} \mathrm{Cr}(\mathrm{VI}))$. Error bars represent the standard deviation of 3 replicates. 

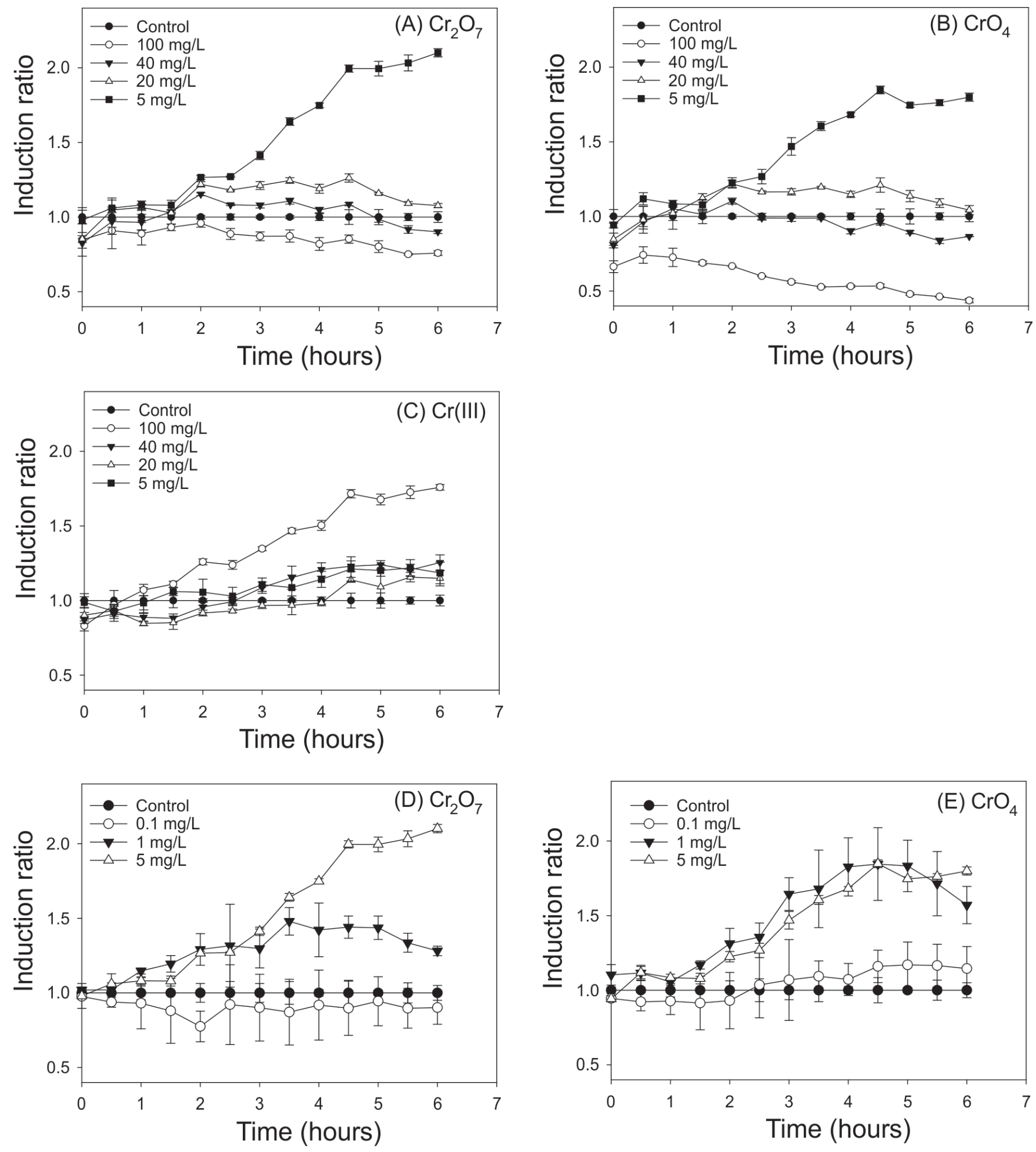

Figure 2: Low concentration of $\mathrm{Cr}(\mathrm{VI})(5 \mathrm{mg} / \mathrm{L})$ from $\mathrm{K}_{2} \mathrm{Cr}_{2} \mathrm{O}_{7}(\mathrm{~A})$ and $\mathrm{K}_{2} \mathrm{CrO}_{4}$ (B) induce bioluminescence of the ADPWH_recA, while high concentrations of $\mathrm{Cr}(\mathrm{VI})(100 \mathrm{mg} / \mathrm{L})$ inhibit it. Higher concentrations of $\mathrm{Cr}(\mathrm{III})(\mathrm{C})$ induce more bioluminescence of the $\mathrm{ADPWH}_{-} r e c \mathrm{~A}$. The induction ratio is proportional to the dose when $\mathrm{Cr}(\mathrm{VI})$ concentration is less than $5 \mathrm{mg} / \mathrm{L}$ (D and E). Error bars represent the standard deviation of 3 replicates. 

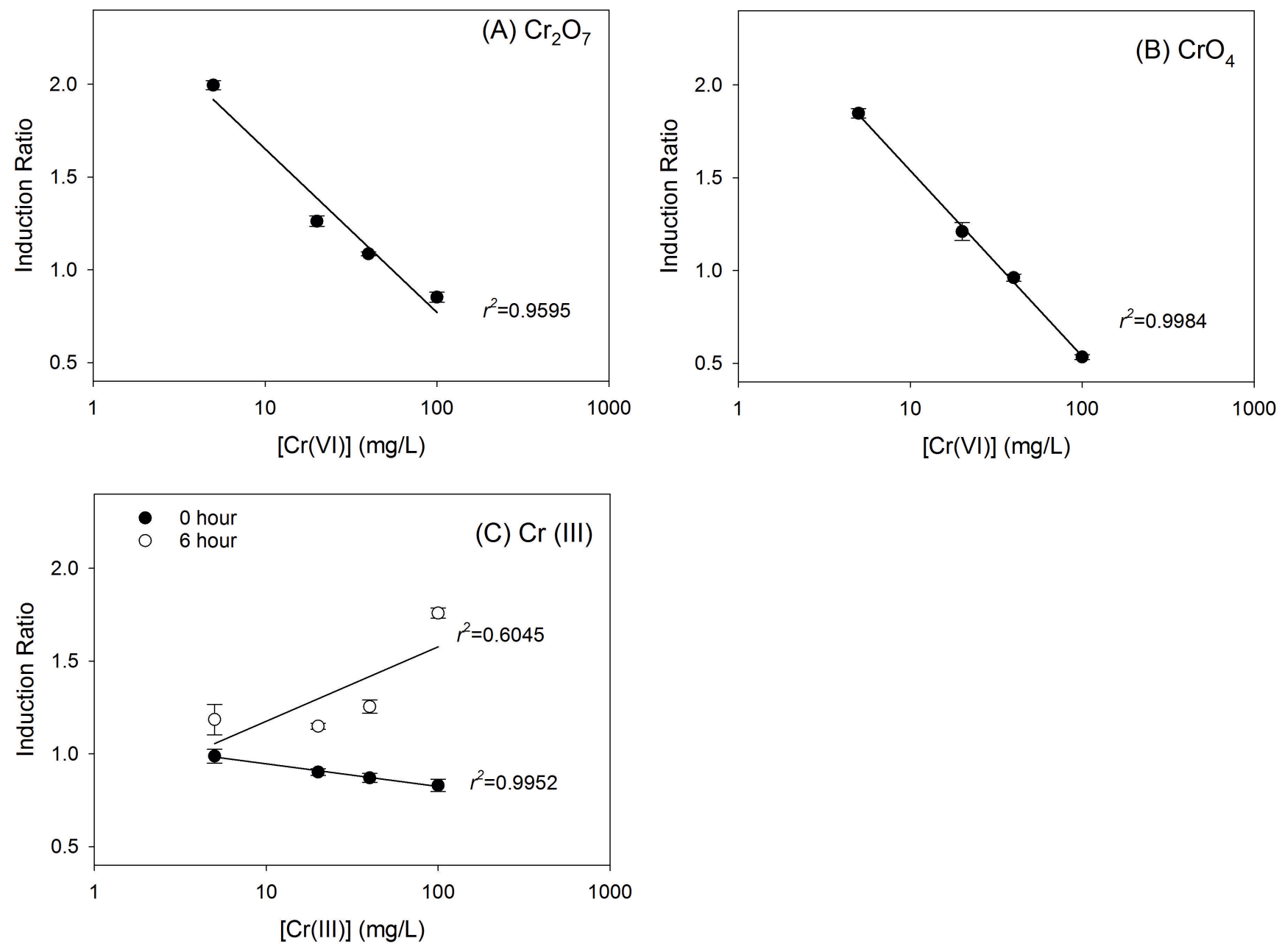

Figure 3: Response of $\mathrm{ADPWH}-\mathrm{rec} \mathrm{A}$ to different concentration of $\mathrm{K}_{2} \mathrm{Cr}_{2} \mathrm{O}_{7}(\mathrm{~A})$ and $\mathrm{K}_{2} \mathrm{CrO}_{4}(\mathrm{~B})$ at 6 hours of experiment and the response of $\mathrm{ADPWH}_{-}$rec $\mathrm{A}$ to different concentration of $\mathrm{Cr}$ (III) (C) in liquid phase at time o and 6 hours. Linear regression curve of the dose-response are drawn (solid line) respectively. Error bars represent the standard deviation of 3 replicates. 

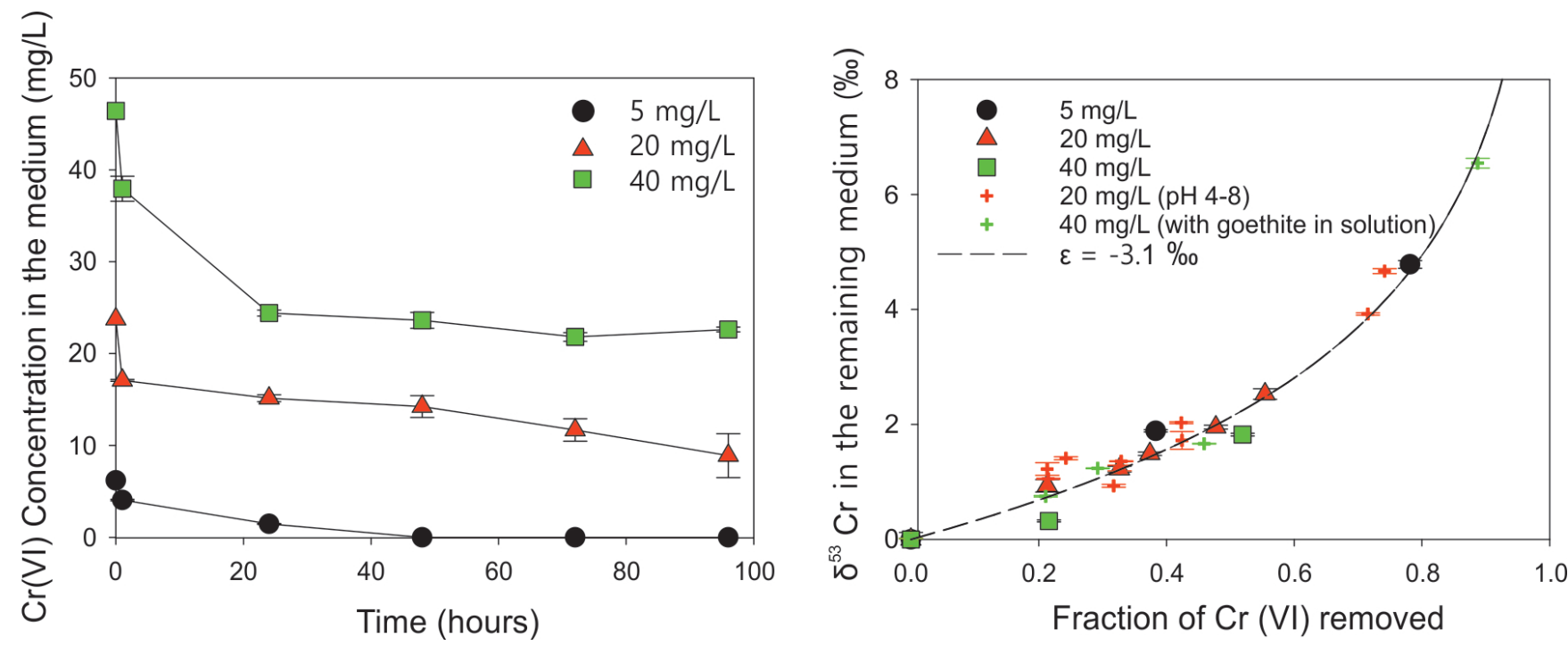

Figure 4: (a): Chromium reduction experiments by Pseudomonas fluorescens LB 300 at high (40 mg/L), medium $(20 \mathrm{mg} / \mathrm{L})$ and low $(5 \mathrm{mg} / \mathrm{L})$ initial Cr concentration. Uncertainties in the experiment are expressed as standard deviation between the triplicates in each experimental group. Controls were prepared with the same amount of dead cells. Uncertainties are shown as standard deviation between the triplicates in each group. (b): Isotope fractionation when reduced by Pseudomonas fluorescens LB 300 with different starting concentration of chromium. The fractionation factor $(\varepsilon=-3.1 \%$ ) is independent with the initial $\mathrm{Cr}(\mathrm{VI})$ concentrations. Data presented as red are from (Zhang et al., 2018), and data presented as green crosses are from (Zhang et al., 2019). Uncertainties are shown as $2 \times$ standard deviation for the measurement. 